\title{
Copper nanoparticles as nanofillers in an adhesive resin system: An in vitro study
}

\section{Nanocząsteczki miedzi jako nanowypełniacze w systemie wiążącym - badanie in vitro}

\author{
Rafael Torres-Rosas ${ }^{1, D-F}$, Nayely Torres-Gómez ${ }^{2,3, B, C, E, F}$, René García-Contreras ${ }^{4, B, C, F}$, Rogelio José Scougall-Vilchis ${ }^{5, A, D-F}$, \\ Luis Roberto Domínguez-Díaz, ${ }^{3, B, B, F}$, Liliana Argueta-Figueroa ${ }^{7, A, B, D, F}$
}

\author{
${ }^{1}$ Laboratory of Biomaterials, Center for Studies in Health and Disease Sciences, School of Dentistry, Benito Juárez Autonomous University of Oaxaca, Oaxaca de Juárez, Mexico \\ ${ }^{2}$ Technological Institute of Toluca, Metepec, Mexico \\ ${ }^{3}$ National Technological Institute of Mexico, Mexico City, Mexico \\ ${ }^{4}$ Laboratory of Interdisciplinary Research, Area of Nanostructures and Biomaterials, National School of Higher Studies León Unit, National Autonomous University of Mexico, Mexico City, Mexico \\ ${ }^{5}$ Department of Orthodontics, Center for Research and Advanced Studies in Dentistry, Autonomous University of Mexico State, Mexico City, Mexico \\ ${ }^{6}$ Technological Institute of Oaxaca, Oaxaca de Juárez, Mexico \\ ${ }^{7}$ Cátedras CONACYT - School of Dentistry, Benito Juárez Autonomous University of Oaxaca, Oaxaca de Juárez, Mexico
}

A - research concept and design; $\mathrm{B}$ - collection and/or assembly of data; $\mathrm{C}$ - data analysis and interpretation;

$D$ - writing the article; $E$ - critical revision of the article; $F$ - final approval of the article

Address for correspondence

Liliana Argueta-Figueroa

E-mail:I_argueta_figueroa@hotmail.com

\section{Funding sources}

Cátedras-CONACYT program. Program for Strengthening Educational Quality 2019 (PFCE), Secretariat of Public Education (SEP).CONACYT (project No. (B-2016-01-284495). UNAM-DGAPA-PAPIIT:IA205518.

Conflict of interest

None declared

Received on February 18, 2020

Reviewed on March 23, 2020

Accepted on May 2, 2020

Published online on September 30, 2020

Cite as

Torres-Rosas R, Torres-Gómez N, García-Contreras R, Scougall-Vilchis RJ, Domínguez-Díaz LR, Argueta-Figueroa L. Copper nanoparticles as nanofillers in an adhesive resin system: An in vitro study. Dent Med Probl. 2020;57(3):239-246. doi:10.17219/dmp/121973

DOI

$10.17219 / \mathrm{dmp} / 121973$

Copyright

○) 2020 by Wroclaw Medical University

This is an article distributed under the terms of the

Creative Commons Attribution 3.0 Unported License (CC BY 3.0) (https://creativecommons.org/licenses/by/3.0/).

\begin{abstract}
Background. The incorporation of an antibacterial agent into an adhesive could improve its clinical performance. Some nanoparticles (NPS), including copper nanoparticles (Cu NPs), display an antibacterial effect. Therefore, Cu NPs could act as a nanofiller when added to an adhesive.

Objectives. The aim of this study was to evaluate the antibacterial activity, cytotoxicity and shear bond strength (SBS) of an experimental dental adhesive with Cu NPS.

Material and methods. Different concentrations ( $0.0050 w t \%, 0.0075 w t \%$ and $0.0100 w t \%)$ of Cu NPs were added to the adhesive. The distribution of Cu NPs in the polymer matrix was observed based on transmission electron microscope (TEM) images. The antimicrobial activity of the adhesive + Cu NPs was evaluated with the agar disk diffusion test against Staphylococcus aureus (S. aureus), Escherichia coli (E. coli) and Streptococcus mutans (S. mutans). The cytotoxicity assay was performed by means of the MTT (3-(4,5-dimethylthiazol-2-yl)-2,5-diphenyltetrazolium bromide) method with human pulp cells (HPC). Additionally, the SBS tests were carried out $(n=31)$ and the modes of fracture were registered. The vestibular and lingual surfaces of each tooth were randomly assigned to the study groups (group I - control adhesive; group $\|$ - adhesive $+0.0100 \mathrm{wt} \%$ (u NPs). The samples were statistically analyzed ( $p \leq 0.05$ ).

Results. The adhesive $+0.0100 \mathrm{wt} \%$ Cu NPs showed inhibition zones against the strains under study that were similar to, or slightly smaller than, the halos produced by chlorhexidine (CHX) and specific drugs for each strain (30 $\mu \mathrm{g}$ of cefotaxime against $S$. mutans and $S$. aureus, and 1.25/3.75 $\mu \mathrm{g}$ of sulfamethoxazole/ trimethoprim against $E$. coli). The control adhesive was moderately cytotoxic (relative cell viability of $36.7 \pm 0.8 \%$ ), being more cytotoxic than Cu NPs themselves $(58.3 \pm 0.1 \%)$. A significantly higher SBS was obtained for the adhesive $+0.0100 \mathrm{wt} \%$ Cu NPs $(6.038 \pm 2.95 \mathrm{MPa})$ than for the control group $(3.278 \pm 1.75 \mathrm{MPa}$ ). The modes of fracture in group I were almost equally distributed between adhesive and cohesive failures whereas in group II, the failure was mainly cohesive.
\end{abstract}


Conclusions. The results of this study suggest that incorporating Cu NPs into an adhesive improves its SBS and provides it with antibacterial properties, without increasing its inherent cytotoxicity -2 desirable characteristics for the dental adhesives of composites.

Key words: copper, nanoparticles, mechanical stress, antibacterial agents, dental bonding

Słowa kluczowe: miedź, nanocząsteczki, naprężenie mechaniczne, czynniki antybakteryjne, wiązanie dentystyczne

\section{Introduction}

Considerable scientific advances have been made in the field of adhesive materials used in restorative esthetic dentistry; however, further improvements, e.g., regarding antibacterial properties, are needed to prevent the undesirable formation of secondary caries lesions. As it is well-known, esthetic dentistry is the current tendency. Patients demand long-lasting and invisible restorations. It has been reported that more than a half of the performed dental restorations are replacements for restorations that failed prematurely. ${ }^{1}$ A fracture in the restoration or dental structures and secondary caries are the main reasons for the failure of dental restorations. ${ }^{2}$ Secondary caries is a frequent concern for dentists in clinical practice, because caries leads to the shortening of the service life of dental restorations, and ultimately results in the need to replace restorative materials. ${ }^{3}$

Ideally, the bond formed at the adhesive-dentin interface should prevent the penetration of noxious substances, such as bacteria, extracellular products or oral fluids. ${ }^{4}$ Thus, there is a need to add an antibacterial agent to dental composites for this purpose. Chlorhexidine (CHX) has been studied in this regard. Studies on composites with increasing concentrations of $\mathrm{CHX}$ dissolved in resin blends have shown a slight adverse effect on the degree of conversion and a $27-48 \%$ decrease in the E-modulus (i.e., a lower polymer stiffness) as compared to controls. ${ }^{5}$ In addition, the incorporation of $1 \% \mathrm{CHX}$ resulted in a reduction in tensile and compressive strengths. ${ }^{6}$ The reason for this finding may be the disruption of the monomer curing process or interference in binding the filler and matrix phases by the incorporated agent. ${ }^{7}$

The application of nanotechnology in the field of dental biomaterials is a great step toward the production of materials with better biological properties. It has been demonstrated that some nanoparticles (NPs) possess an antibacterial effect. ${ }^{8}$ In brief, the main variables that are involved in antibacterial activity are the particle size, nanostructure shape, dosage, and chemical composition. With regard to the impact of the size on antibacterial activity, NPs must be small enough to penetrate cell membranes and affect intracellular homeostasis. Besides, the interaction between NPs and bacteria depends on the surface area exposed (small particles with a larger available interaction surface area exert a greater bactericidal effect than large-sized particles). ${ }^{9}$ More specifically, the antibacterial mechanism depends on the chemical composition of NPs. Particular attention has been paid to the study of metal NPs, such as $\mathrm{Au},{ }^{10} \mathrm{Ag},{ }^{11} \mathrm{Zn},{ }^{12}$ and $\mathrm{Cu} .{ }^{13}$ However, $\mathrm{Cu}$ costs significantly less than $\mathrm{Ag}$ or $\mathrm{Au}$, making it attractive from an economic standpoint. ${ }^{14}$ The antibacterial mechanisms of $\mathrm{Cu}$ NPs have been explained through the production of hydroxyl and superoxides via Fenton reactions, and through binding the disulfide groups of respiratory enzymes in the cellular membrane, leading to the formation of a complex with $\mathrm{Cu}$ NPs; both mechanisms result in the disruption of the cell cycle. ${ }^{15}$

The antibacterial properties of $\mathrm{Cu}$ NPs have been studied previously. ${ }^{13,14}$ One study indicated the potential use of $\mathrm{Cu}$ NPs in the field of dental biomaterials; $\mathrm{Cu}$ NPs were prepared with a simple chemical method, and their antibacterial activity was tested against Staphylococcus aureus (S. aureus), Escherichia coli (E. coli) and Streptococcus mutans (S. mutans). ${ }^{16}$ Additionally, it has been reported that using NPs as nanofillers could contribute to higher modulus of elasticity and shear bond strength (SBS) values for dental adhesives. ${ }^{17}$

The aim of the present study was to investigate the antibacterial activity, cytotoxicity and SBS of a novel dental adhesive enriched with $\mathrm{Cu}$ NPs as nanofillers.

\section{Material and methods}

The type of adhesive system used for the experiments was a two-step, single-component, etch-and-rinse, lightcure dental adhesive (Adper ${ }^{\mathrm{TM}}$ Single Bond Plus Adhesive; 3M ESPE, St. Paul, USA). This adhesive is hydrophilic, and its solvent contains ethyl alcohol (25-35\%) and water $(<5 \%)$. As mentioned above, $\mathrm{Cu}$ NPs were synthesized. A solution consisting of deionized water and cupric sulfate pentahydrate $\left(\mathrm{CuSO}_{4} \cdot 5 \mathrm{H}_{2} \mathrm{O}\right)$ at a concentration of $1 \times 10^{-2} \mathrm{M}$ was prepared, and the $\mathrm{pH}$ of the solution was adjusted with sodium hydroxide $(\mathrm{NaOH})$. Later, the metal salt solution was bubbled with nitrogen $\left(\mathrm{N}_{2}\right)$ for $30 \mathrm{~min}$. Sodium borohydride $\left(\mathrm{NaBH}_{4}\right)$ was added at a stoichiometric concentration as a reducing agent. After that, the preparation was stirred for $120 \mathrm{~min}$ to finish the reaction. Subsequently, the precipitate was washed 3 times with distilled water and filtered. Then, the product was washed with acetone to displace water and isopropyl alcohol was added to avoid oxidation. ${ }^{16}$ The $\mathrm{Cu}$ NPs (average particle size $=3.97 \mathrm{~nm}$; range: $2-10 \mathrm{~nm}$ ) were suspended in the same dilutant for all the experiments described below. For the experimental group, the $\mathrm{Cu}$ NPs were added to the dental adhesive and mixed using a vortex agitator in order to completely and uniformly distribute them. 


\section{Distribution of nanoparticles in the adhesive}

The ultrastructure and qualitative analyses were carried out using the transmission electron microscope (TEM) JEM-2100 (JEOL Ltd., Tokyo, Japan). Micrographs were created to observe the distribution and size of the $\mathrm{Cu}$ NPs dispersed in the polymerized adhesive.

\section{Antibacterial test}

Antibacterialactivitywas determinedusingtheagardisk diffusion method, following the recommendations of the National Committee for Clinical Laboratory Standards. ${ }^{18}$ Copper nanoparticles were added to the dental adhesive at 3 different concentrations: $0.0050 \mathrm{wt} \% ; 0.0075 \mathrm{wt} \%$; and $0.0100 \mathrm{wt} \%$. The turbidity of the culture was adjusted with sterile saline to achieve a value equivalent to a 0.5 McFarland standard. Mueller-Hinton agar plates were prepared and inoculated with $200 \mu \mathrm{L}$ of suspension containing the standardized quantity of bacteria. Each disk was prepared with $20 \mu \mathrm{L}$ of $\mathrm{CHX}$ or the adhesive with 3 different concentrations of Cu NPs. The disks were firmly placed one by one on the inoculated agar plates.

The antibacterial test was done against 3 strains: $S$. aureus; E. coli; and S. mutans. The antibacterial activity of the adhesive was determined using 2 groups for each strain: a non-polymerized adhesive; and an adhesive polymerized for $20 \mathrm{~s}$ with a light-emitting diode (LED) (Ortholux ${ }^{\circledR}$ XT; 3M Unitek Corp., Monrovia, USA). Two positive controls were used: $0.2 \% \mathrm{CHX}$ and specific drugs for each strain (30 $\mu$ g of cefotaxime against S. mutans and S. aureus, and $1.25 / 3.75 \mu \mathrm{g}$ of sulfamethoxazole/trimethoprim against E. coli). The control adhesive without $\mathrm{Cu}$ NPs was tested against the same bacteria under study.

Inhibition zones were measured on a standardized photograph using a millimeter scale for calibration. The measurements were taken using the ImageJ $1.47 \mathrm{e}$ software (National Institutes of Health, USA) and the average result was rounded to the nearest millimeter. Each experiment was done in triplicate.

\section{Cytotoxicity assay}

The protocol for this study was approved by the Bioethics Committee at the National School of Higher Studies León Unit, National Autonomous University of Mexico in Mexico City, Mexico, with the assigned number CE_16/004_SN. A 21-year-old patient, who had previously given informed consent, donated the tissues obtained from a third molar surgery. Human pulp cells (HPC) were isolated from the pulp tissue of the teeth. The cultures were used for the subsequent assays according to the methodology previously reported for our research group. ${ }^{19}$ The tests were performed using approx. $2 \times 10^{5}$ cells $/ \mathrm{mL}$ per well. The adhesives contained
$\mathrm{Cu}$ NPs at the same concentrations as those used in the antibacterial tests described above. Serial dilutions were made. The test was performed with indirect contact and cell viability was determined by means of the MTT (3-(4,5-dimethylthiazol-2-yl)-2,5-diphenyltetrazolium bromide) method. Cytotoxicity was rated according to ISO standard 10993-5. Reproducible data was obtained in triplicate in 3 independent trials.

\section{Shear bond strength}

Thirty-one freshly extracted and healthy human third molars (without caries and restoration-free) were cleaned with a rotary brush and stored in a $0.2 \%$ solution of thymol at $4^{\circ} \mathrm{C}$ until further use. Each molar was carefully placed into an acrylic mold until the vestibular and lingual surfaces were parallel to the mold base, which is the appropriate position for performing the SBS test. The enamel of the vestibular and lingual surfaces was cut with a carbide disk under irrigation. Then, the surfaces were pumiced with a fluoride-free paste and rubber prophylactic cups, washed with water, and then air-dried. The surfaces of the teeth were randomly assigned to the control and experimental groups. Thus, it was possible to make a paired comparison between the groups. In both groups, the dentin was conditioned with phosphoric acid at a concentration of $37 \%$, rinsed with water for $30 \mathrm{~s}$ and dried with contaminant-free air. In group I (control group), a thin coat of the dental adhesive was applied. In group II (experimental group), the adhesive with 0.0100 wt\% of Cu NPs was used to test SBS, as it was the experimental adhesive which showed the strongest antibacterial effect out of all the concentrations of the $\mathrm{Cu}$ NPs tested. Pre-formed resin blocks $5 \mathrm{~mm} \times 5 \mathrm{~mm} \times 1 \mathrm{~mm}$ (Filtek ${ }^{\circledR}$ Z250 XT, 3M ESPE), light-cured using Ortholux XT for $20 \mathrm{~s}$, were placed on the vestibular and lingual surfaces of each tooth. The samples were incubated in distilled water at $37^{\circ} \mathrm{C}$ for $24 \mathrm{~h}$. For the test, a universal testing machine (Autograph AGS X; Shimadzu Corp., Tokyo, Japan) with a crosshead speed of $0.5 \mathrm{~mm} / \mathrm{min}$ was used. An occluso-gingival load was applied to the resin blocks using a chisel-edge plunger, producing a shear load at the resin-tooth interface; the maximum load was recorded in megapascals $(\mathrm{MPa})$.

\section{Failure modes}

To perform the qualitative analysis of the type of debonding between the adhesive and the dentin, the failure modes were classified as adhesive, cohesive, or mixed. For each sample, the failure modes were recorded according to the following criteria:

- adhesive failure occurs when the fracture mainly appears at the tooth-composite interface, i.e., the dentin surface remains exposed in over $75 \%$ of the bonded area; 
- cohesive failure occurs when the fracture mainly appears within the composite, i.e., when over $75 \%$ of the bonded area exhibits the fractured composite;

- mixed failure occurs when $25-75 \%$ of the bonded area shows both adhesive and cohesive failure. ${ }^{20}$

In addition, the fracture surfaces were examined. The micrographs of different zones on the sample surface were obtained using the scanning electron microscope (SEM) JSM-6510LV (JEOL Ltd.) at $20 \mathrm{keV.} \mathrm{Mag-}$ nification varied between $\times 100$ and $\times 200$.

\section{Statistical analysis}

The data is expressed as mean $(M) \pm$ standard deviation $(S D)$. The Shapiro-Wilk test (for the normality of data) was performed for the outcomes to determine the subsequent test (parametric or nonparametric). For the antibacterial and cytotoxicity results, multiple comparisons were performed with the Mann-Whitney $U$ tests. For SBS, Student's $t$ test was used to determine the difference of means. For the mode of failure, the $X^{2}$ test was applied. The IBM SPSS Statistics for Windows software, v. 22.0 (IBM Corp., Armonk, USA) was used for the statistical analysis. Differences were statistically significant at $p \leq 0.05$.

\section{Results}

\section{Distribution of nanoparticles in the adhesive}

Figure 1 shows the distribution of $\mathrm{Cu}$ NPs in the adhesive. The shape of $\mathrm{Cu}$ NPs was almost spherical, allowing for a greater surface-area-to-volume ratio, which makes NPs more reactive, and consequently, their antibacterial effect is exhibited. ${ }^{16,21}$ Adding the polymer does not cause any changes in size or morphology. The distribution of $\mathrm{Cu}$ NPs in the adhesive was homogeneous and showed no agglomeration.


Fig. 1. Distribution of copper nanoparticles (Cu NPs) in the adhesive Representative images at 2 magnifications - scale bar: $20 \mathrm{~nm}$ (A); and scale bar: $50 \mathrm{~nm}$ (B).

\section{Antibacterial test}

Figure 2 and Table 1 show the observed antibacterial effects. The experimental adhesive containing $0.0100 \mathrm{wt} \%$ of $\mathrm{Cu}$ NPs demonstrated the highest antibacterial activity and the obtained results are comparable with the antibacterial effect of $\mathrm{CHX}$. The adhesives containing 0.0075 wt $\%$ and $0.0050 \mathrm{wt} \%$ of Cu NPs showed slight inhibition zones.

\section{Cytotoxicity assay}

Figure 3 and Table 2 show the results of the cytotoxicity assay. This test indicated that the adhesive is more cytotoxic than $\mathrm{Cu}$ NPs themselves. The control adhesive (without $\mathrm{Cu}$ NPs) is moderately cytotoxic, according to ISO standard 10993-5. There were no significant differences between the cell viability of the adhesives with $\mathrm{Cu}$ NPs as compared to the adhesive without $\mathrm{Cu}$ NPs. This indicates that $\mathrm{Cu}$ NPs do not increase the inherent cytotoxicity of the adhesive.
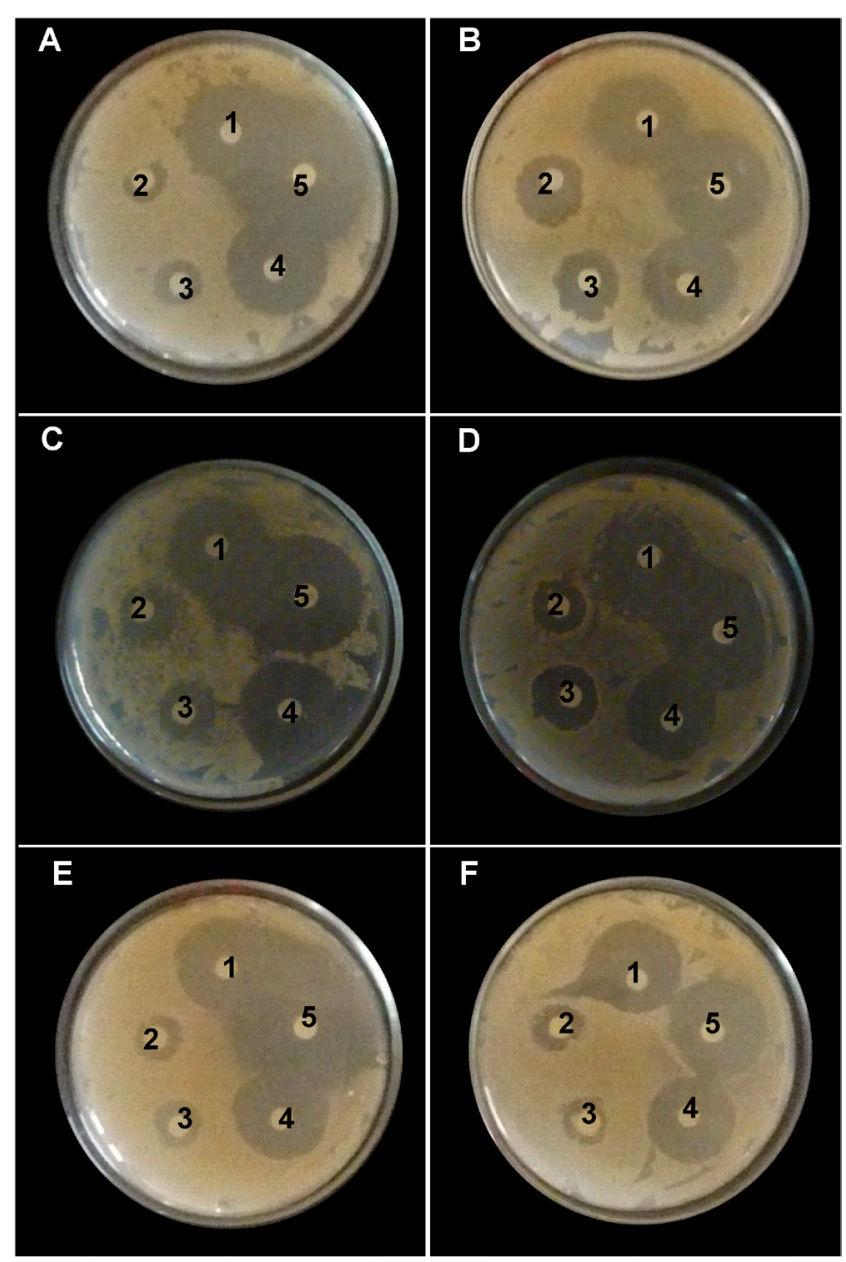

Fig. 2. Results of the antibacterial test using the agar disk diffusion method $A, C$ and $E$ - agar plates showing disks with the non-polymerized adhesive; $\mathrm{B}, \mathrm{D}$ and $\mathrm{F}$ - agar plates showing disks with the polymerized adhesive; $1-0.2 \%$ CHX; 2 - adhesive + 0.0050 wt $\%$ Cu NPs; 3 - adhesive + 0.0075 wt $\%$ Cu NPs; 4 - adhesive + 0.0100 wt\% Cu NPs; 5 - specific drugs for each strain; CHX - chlorhexidine; Cu NPs - copper nanoparticles. 
Table 1. Inhibition zones produced by different concentrations of the copper nanoparticles (Cu NPs) added to the adhesive and by the controls

\begin{tabular}{|c|c|c|c|c|c|c|}
\hline \multirow{3}{*}{ Adhesive } & \multicolumn{6}{|c|}{ Inhibition zones [mm] } \\
\hline & non-polymerized & polymerized & non-polymerized & polymerized & non-polymerized & polymerized \\
\hline & \multicolumn{2}{|c|}{ S. aureus* } & \multicolumn{2}{|c|}{ E. coli** } & \multicolumn{2}{|c|}{ S. mutans* } \\
\hline Adh + 0.0 wt\% Cu NPs & $0 \pm 0^{\mathrm{Aa}}$ & $0 \pm 0^{\mathrm{Aa}}$ & $0 \pm 0^{\mathrm{Aa}}$ & $0 \pm 0^{\mathrm{Aa}}$ & $0 \pm 0^{\mathrm{Aa}}$ & $0 \pm 0^{\mathrm{Aa}}$ \\
\hline Adh + 0.0050 wt $\%$ Cu NPs & $0 \pm 0^{A a}$ & $12 \pm 1.0^{\mathrm{Bb}}$ & $11 \pm 1.5^{\mathrm{Bb}}$ & $9 \pm 1.9^{\mathrm{Bb}}$ & $10 \pm 1.1^{\mathrm{Bb}}$ & $10 \pm 1.4^{\mathrm{Bb}}$ \\
\hline Adh + 0.0075 wt $\%$ Cu NPs & $10 \pm 1.5^{\mathrm{Ba}}$ & $12 \pm 1.8^{\mathrm{Ba}}$ & $13 \pm 1.1^{\mathrm{Ba}}$ & $14 \pm 2.0^{\mathrm{Ba}}$ & $12 \pm 1.4^{\mathrm{Ba}}$ & $13 \pm 1.6^{\mathrm{Ba}}$ \\
\hline Adh + 0.0100 wt $\%$ Cu NPs & $24 \pm 1.7^{\mathrm{Ca}}$ & $21 \pm 1.9^{c b}$ & $24 \pm 1.3^{\mathrm{Ca}}$ & $20 \pm 0.9^{c b}$ & $27 \pm 1.4^{\mathrm{Ca}}$ & $25 \pm 1.5^{\mathrm{Ca}}$ \\
\hline $\mathrm{CHX}(0.2 \%)$ & $24 \pm 1.5^{\mathrm{Ca}}$ & $24 \pm 1.2^{\mathrm{Ca}}$ & $25 \pm 0.9^{\mathrm{Ca}}$ & $24 \pm 0.5^{\mathrm{Da}}$ & $24 \pm 0.3^{\mathrm{Da}}$ & $24 \pm 1.6^{\mathrm{Ca}}$ \\
\hline Specific drug & $27 \pm 1.9^{\mathrm{Ca}}$ & $25 \pm 1.9^{\mathrm{Ca}}$ & $27 \pm 1.4^{\mathrm{Ca}}$ & $28 \pm 1.7^{\text {Еа }}$ & $29 \pm 1.8^{\mathrm{Ca}}$ & $27 \pm 1.4^{\mathrm{Ca}}$ \\
\hline
\end{tabular}

Data presented as mean $(M) \pm$ standard deviation (SD).

Adh - adhesive; S. aureus - Staphylococcus aureus; E. coli - Escherichia coli; S. mutans - Streptococcus mutans; ${ }^{*}$ specific drug -cefotaxime (30 $\mu$ g); ${ }^{* *}$ specific drugs - sulfamethoxazole/trimethoprim $(1.25 / 3.75 \mu \mathrm{g})$. The same letters show that there are no statistically significant differences. Upper-case letters indicate differences between different concentrations of Cu NPs, while lower-case letters denote differences between the strains (Mann-Whitney $U$ test; $p \leq 0.05$ ).

Table 2. Results of the cytotoxicity assay (cell viability [\%]) for the adhesives enriched with copper nanoparticles (Cu NPs) using the MTT method

\begin{tabular}{|c|c|c|c|c|c|}
\hline Serial dilutions [\%] & Adh + $0.0 w t \%$ Cu NPs & Adh $+0.0050 w t \%$ Cu NPs & Adh + 0.0075 wt $\%$ Cu NPs & Adh $+0.0100 w t \%$ Cu NPs & Cu NPs \\
\hline 0 (control) & - $100.0 \pm 4.9^{\mathrm{Aa}}$ & - $100.0 \pm 0.3^{\mathrm{Aa}}$ & $\mathbf{D} 100.0 \pm 1.8^{\mathrm{Aa}}$ & - $100.0 \pm 0.3^{\mathrm{Aa}}$ & $\mathbf{E} 100.0 \pm 0.1^{\mathrm{Aa}}$ \\
\hline 0.78125 & $\mathbf{\square} 86.2 \pm 3.2^{\mathrm{Ab}}$ & $\mathbf{\square} 87.2 \pm 1.3^{\mathrm{Ab}}$ & $\mathbf{a} 77.0 \pm 2.7^{\mathrm{Bb}}$ & $\mathbf{\Delta} 70.6 \pm 1.0^{\mathrm{cb}}$ & $\mathbf{\square} 99.7 \pm 0.3^{\mathrm{Da}}$ \\
\hline 1.5625 & $\mathbf{\Delta} 59.5 \pm 4.0^{\mathrm{AC}}$ & $47.9 \pm 5.1^{\mathrm{BC}}$ & $47.8 \pm 4.6^{\mathrm{BC}}$ & $43.3 \pm 1.9^{B C}$ & 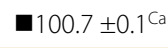 \\
\hline 3.125 & $38.6 \pm 6.6^{\mathrm{Ad}}$ & $35.2 \pm 2.0^{A C}$ & $33.4 \pm 0.8^{\mathrm{Ad}}$ & $36.8 \pm 2.0^{\mathrm{Ad}}$ & $\mathbf{\square} 96.7 \pm 0.1^{\mathrm{Bb}}$ \\
\hline 6.25 & $34.6 \pm 1.5^{\mathrm{Ae}}$ & $37.0 \pm 1.0^{\mathrm{AC}}$ & $34.3 \pm 0.6^{\mathrm{Ad}}$ & $37.7 \pm 1.1^{\mathrm{Ad}}$ & $\mathbf{\square} 83.5 \pm 0.2^{B C}$ \\
\hline 12.5 & $35.1 \pm 1.6^{\mathrm{Ae}}$ & $39.8 \pm 2.2^{\mathrm{Ad}}$ & $34.6 \pm 0.6^{\mathrm{Ad}}$ & $41.2 \pm 3.6^{\mathrm{Ad}}$ & $82.5 \pm 0.2^{\mathrm{Bd}}$ \\
\hline 25 & $36.5 \pm 4.0^{\mathrm{Ae}}$ & $39.4 \pm 1.0^{\mathrm{Ad}}$ & $38.5 \pm 2.4^{\mathrm{Ad}}$ & $37.1 \pm 1.5^{\mathrm{Ad}}$ & $\mathbf{\Delta} 63.5 \pm 0.1^{\mathrm{Be}}$ \\
\hline 50 & $36.7 \pm 0.8^{\mathrm{Ae}}$ & $39.8 \pm 0.6^{\mathrm{Bd}}$ & $37.3 \pm 0.1^{\mathrm{Ad}}$ & $\Delta 1.0 \pm 1.5^{\mathrm{Bd}}$ & $\Delta 58.3 \pm 0.1^{\mathrm{cf}}$ \\
\hline
\end{tabular}

Data presented as mean $(M) \pm$ standard deviation (SD).

Cytotoxicity was rated according to ISO standard 10993-5 as: $\mathbf{n}$ non-cytotoxic; $\boldsymbol{\Delta}$ slightly cytotoxic; $\boldsymbol{\bullet}$ moderately cytotoxic; and $\boldsymbol{\bullet}$ severely cytotoxic. The same letters show that there are no statistically significant differences. Upper-case letters indicate differences within a group (wt\% Cu NPs) in the same dilution, while lower-case letters denote differences between the dilutions (Mann-Whitney $U$ test; $p \leq 0.05$ ).

Statistically significant differences $(p \leq 0.05)$ were observed between $\mathrm{Cu}$ NPs and the control adhesive as well as the adhesive enriched with $\mathrm{Cu}$ NPs at different concentrations.

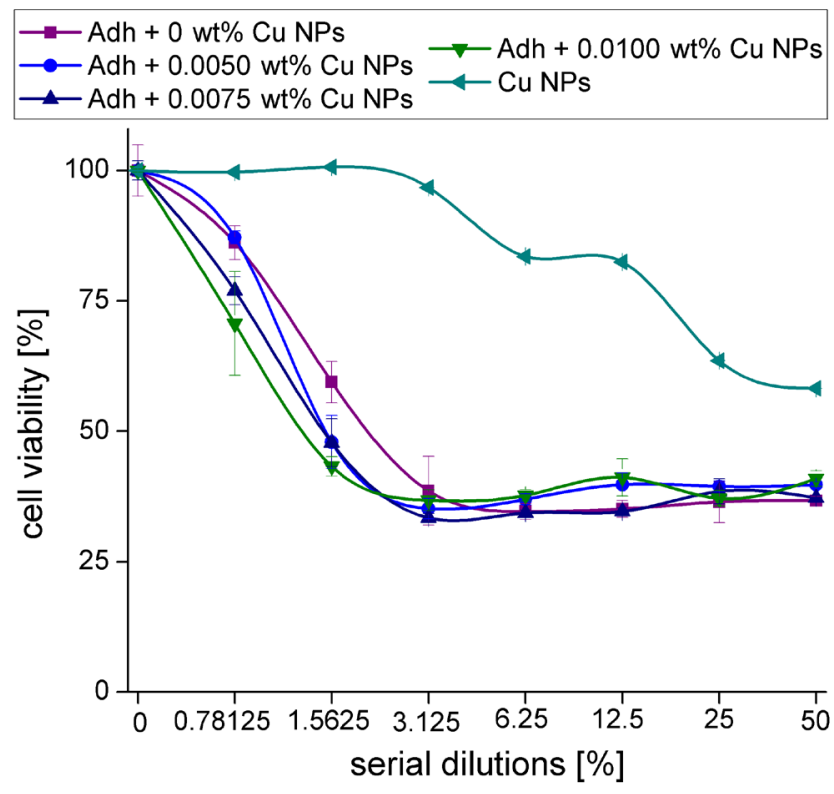

Fig. 3. Relative cell viability results of the cytotoxicity assay

\section{Shear bond strength}

Table 3 shows the SBS values and descriptive statistics. The mean SBS of group II was significantly higher than that of group I $(6.038 \pm 2.95 \mathrm{MPa}$ and $3.278 \pm 1.75 \mathrm{MPa}$, respectively; $p=0.0001$ ). Thus, the $\mathrm{Cu}$ NPs incorporated into the adhesive significantly increased its SBS.

Table 3. Comparison of the shear bond strength (SBS) of the adhesive between the control (I) and experimental (II) groups

\begin{tabular}{|l|c|c|c|c|c|}
\hline Group & $n$ & $\begin{array}{c}\text { SBS } \\
{[\mathrm{MPa}]}\end{array}$ & $\begin{array}{c}\text { Maximum } \\
{[\mathrm{MPa}]}\end{array}$ & $\begin{array}{c}\text { Minimum } \\
{[\mathrm{MPa}]}\end{array}$ & $p$-value \\
\hline Group I & 31 & $3.278 \pm 1.75$ & 20.47300 & 3.89819 & 0.0001 \\
\hline Group II & 31 & $6.038 \pm 2.95$ & 40.59340 & 6.78409 & \\
\hline
\end{tabular}

Data presented as mean $(M) \pm$ standard deviation (SD). $\mathrm{df}($ degrees of freedom $)=30$; Student's $t$ test.

\section{Failure modes}

Table 4 shows the values which indicate the amount of the adhesive remaining after the SBS test. In this study, there was a significant difference in the debonding pattern between the groups. The modes of fracture were classified as adhesive, cohesive and mixed failure (Fig. 4). 
The modes of fracture in group I were almost equally distributed between adhesive and cohesive failures whereas in group II, the failure was mainly cohesive $(p \leq 0.0001)$.

Table 4. Frequency and distribution of the adhesive failure for the control adhesive and for the adhesive enriched with copper nanoparticles (Cu NPs)

\begin{tabular}{|l|c|c|}
\multicolumn{1}{c|}{$\begin{array}{c}\text { Type of adhesive } \\
\text { failure* }\end{array}$} & Control adhesive & Adhesive with Cu NPs \\
\hline Adhesive failure & 11 & 3 \\
Cohesive failure & 12 & 19 \\
Mixed failure & 8 & 9 \\
Total $n$ & 31 & 31 \\
\hline
\end{tabular}

${ }^{*} X^{2}=27.66 ; \mathrm{df}=4$ ( $\chi^{2}$ test; $\left.p \leq 0.0001\right)$.
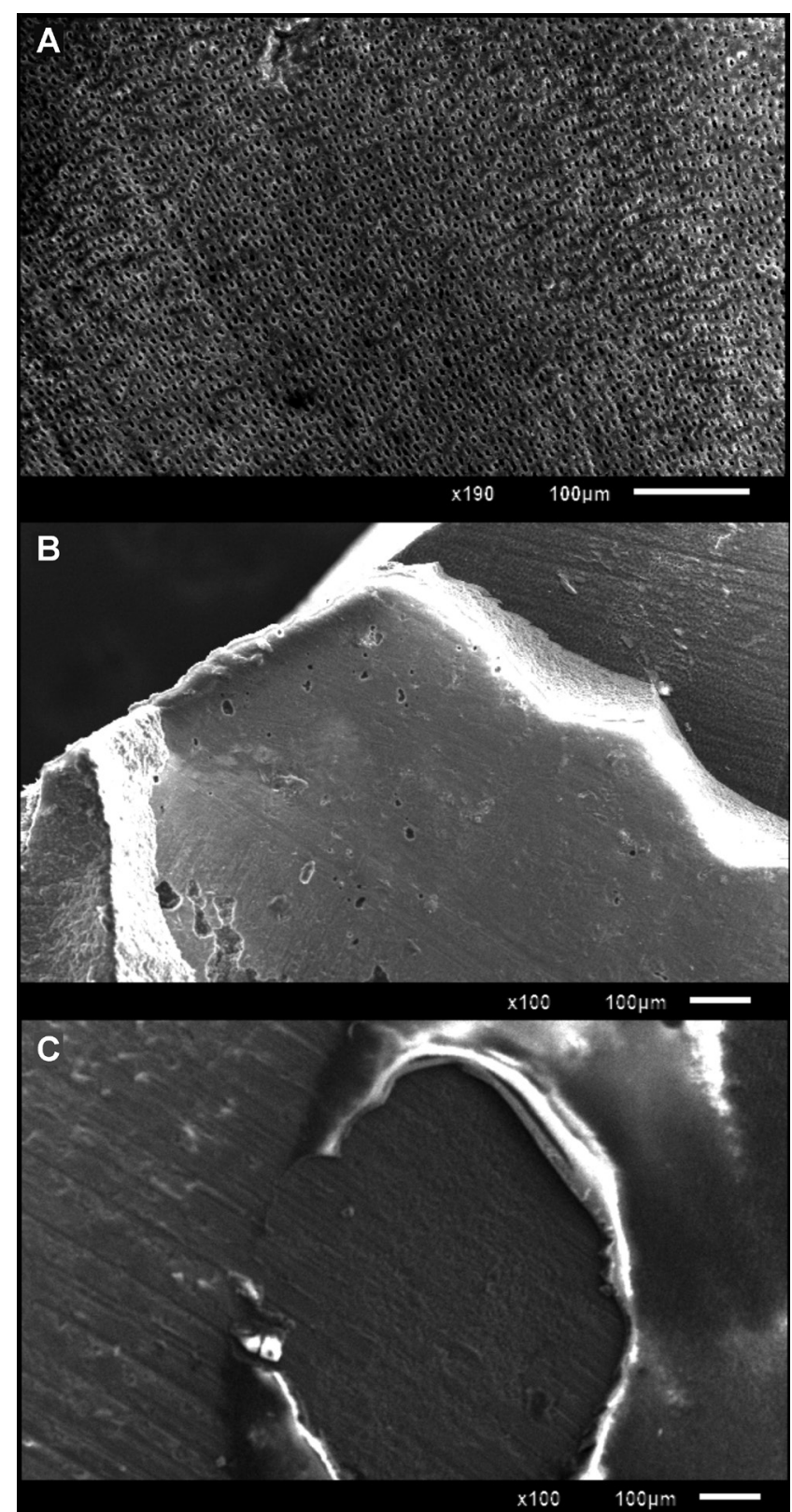

Fig. 4. Representative failure modes from scanning electron microscope (SEM) images

A - adhesive; $\mathrm{B}$ - cohesive; $\mathrm{C}$ - mixed.

\section{Discussion}

In the present study, the experimental adhesive enriched with $\mathrm{Cu}$ NPs exhibited an antibacterial effect against the Gram-positive and Gram-negative strains under study. The antibacterial activity of NPs is related to their concentration, size, shape, and surface chemistry as well as environmental factors. Not only it is well-known that the antibacterial activity of NPs is dose-dependent, as a larger concentration of NPs releases more ions, but their maximum efficacy also depends on the other factors. It has been suggested that the ability of NPs to bind with bacteria is determined by their surface size as well as their potential to infiltrate the bacterial wall, causing irreversible cell damage. ${ }^{14}$ Smaller NPs possess a larger surface area, making it possible to interact more effectively with bacteria and resulting in more pronounced bactericidal activity. Similarly, it has been confirmed, experimentally, that a lower particle size results in a stronger antimicrobial effect. ${ }^{22}$ Such data points to the importance of controlling the size of NPs during synthesis for their successful use. ${ }^{23,24}$ Furthermore, the shape of NPs can help to interact with the bacterial wall, triggering direct contact injury. ${ }^{25}$ Also, NPs induce oxidative stress to prokaryotic cell walls by producing reactive oxygen species. ${ }^{15}$ However, further studies are required in order to determine all the mechanisms involved in the bactericidal effect of NPs. Even with an adhesive with antibacterial activity, a proper adhesion of the composite is necessary for extending the life of the restoration, preventing microfiltration, and therefore preventing the formation of secondary caries in a long term.

The dentin is a tissue that contains water and commonly has a film of odontoblast tubular fluid on the cut surface. In contrast, the resin composite is a hydrophobic material, and therefore is relatively incompatible with the dentin. ${ }^{26}$ The dentin surfaces are connected to the pulp through dentinal tubules. One of the concerns about the use of NPs is their potential toxicity. Nevertheless, the dental adhesive penetrates only a few micrometers (about $10 \mu \mathrm{m}$ ) into the dentin, which could prevent damage to the pulp tissue. ${ }^{27}$ Since NPs are embedded in the adhesive, they are probably unable to migrate into the pulp tissue. In fact, it would be advisable to use the same precautions to protect the pulp when it is in close proximity to any direct restoration. The cytotoxicity results showed that the control adhesive was moderately cytotoxic (relative cell viability: $36.7 \pm 0.8 \%$ ); the adhesive with $0.100 \mathrm{wt} \%$ of $\mathrm{Cu}$ NPs was also moderately cytotoxic, but cell viability was higher $(41.0 \pm 1.5 \%)$, showing a significant difference between these adhesives $(p \leq 0.05)$. In the future, the toxic effect in an animal model could be tested to determine the fate of NPs and corroborate our assumption.

The studied adhesive has the following chemical composition: bisphenol A-glycidyl methacrylate (Bis-GMA); 2-hydroxyethyl methacrylate (HEMA); dimethacrylates; polyalkenoic acid; copolymer; initiator; $34 \%$ water; 
and ethanol. The vehicle used for $\mathrm{Cu}$ NPs was isopropanol. Thus, the chosen adhesive system contained HEMA - for its hydrophilicity - and ethanol, which exhibits an affinity for isopropanol. When the dentin is attacked by phosphoric acid, it reacts with the inorganic part of the dentin tissue. The type 1 collagen fibers, which mainly constitute the organic portion of the dentin, become exposed. By placing the adhesive in the tooth cavity, the HEMA molecules in the adhesive interact with glycine amino acid sites, forming an electrostatic-type hydrogen bond between the oxygen of the carboxyl group of glycine and the hydrogen of the hydroxyl group of HEMA. ${ }^{28}$ Nanoparticles, due to their total charge, are very unlikely to affect the binding sites for hydrogen bonds.

On the other hand, if the polymerization shrinkage is reduced, there is a greater possibility of forming hydrogen bonds between the collagen fibers and the adhesive. Such shrinkage is due to the arrangement of polymer chains and the evaporation of the solvent during polymerization. The remaining space could be occupied by fillers such as NPs, thus preventing the shrinkage of the polymeric adhesive. This effect is reflected in the increased resistance to debonding. ${ }^{29}$ However, further studies should be performed in order to confirm the role of Cu NPs in the polymerization process of this adhesive.

In a previous study on an orthodontic adhesive, it was observed that varying the weight percentage of nanofillers in the adhesive favorably influenced the debonding characteristics. When the amount of nanofillers exceeds a certain weight fraction of the adhesive, the strength of the polymer is reduced. ${ }^{30}$ Also, it has been reported that the addition of NPs improves the coefficient of thermal expansion of the polymer, making it more dimensionally stable. ${ }^{31}$ In the present study, SBS increased noticeably with the addition of $0.0100 \mathrm{wt} \%$ of $\mathrm{Cu}$ NPs into the experimental adhesive as compared to the controls.

The main mechanism for the adhesion of the resin composites is the micromechanical retention. Some authors have claimed that the interactions between the adhesive and the dentin molecules play an important role in adhesion, ${ }^{23,24}$ but the chemical bond between the hydroxyl or carboxyl groups of the monomer and the hydroxyapatite hydroxyl groups are electrostatic interactions, at best, such as van der Waals forces or hydrogen bonds. ${ }^{32}$

According to the failure modes, the amount of the adhesive remaining in the dentin was higher in the experimental group than in the control group, indicating that adhesion between the dentin and the adhesive increased with the addition of $\mathrm{Cu}$ NPs. It is important to note that a SBS value cannot be considered a material property. ${ }^{33}$ Therefore, the absolute test values cannot be compared with the data gathered in other studies. Only relative study outcomes, in the sense of "one is better than the other", are a valid basis for further interpretation of the results. ${ }^{34}$

Finally, obtaining the desired properties of nanocomposites requires the homogeneous dispersion of the filler within the polymer matrix. The propensity of NPs to form agglomerates can seriously impact their properties; it depends on the synthesis method and the stability of the particles. In this work, the TEM images show an adequate dispersion of $\mathrm{Cu}$ NPs within the adhesive. However, further studies are needed to determine the toxicity in vivo of these NPs in dental restorative applications.

\section{Conclusions}

The results of this study suggest that incorporating $\mathrm{Cu}$ NPs into an adhesive improves its SBS and provides it with an antibacterial effect, without increasing its inherent cytotoxicity - 2 desirable characteristics for the dental adhesives of composites.

\section{ORCID iDs}

Rafael Torres-Rosas (D) https://orcid.org/0000-0002-5934-003X Nayely Torres-Gómez (1) https://orcid.org/0000-0002-3945-2552 René García-Contreras (1) https://orcid.org/0000-0003-3504-5519 Rogelio José Scougall-Vilchis (D) https://orcid.org/0000-0003-4671-0748 Luis Roberto Domínguez-Díaz (i) https://orcid.org/0000-0003-1935-3239 Liliana Argueta-Figueroa (D) https://orcid.org/0000-0002-1044-6757

\section{References}

1. Beazoglou T, Eklund S, Heffley D, Meiers J, Brown LJ, Bailit H. Economic impact of regulating the use of amalgam restorations. Public Health Rep. 2007;122(5):657-663.

2. Avoaka-Boni MC, Djolé SX, Kaboré WAD, Gnagne-Koffi YND, Koffi AFE. The causes of failure and the longevity of direct coronal restorations: A survey among dental surgeons of the town of Abidjan, Côte d'Ivoire. J Conserv Dent. 2019;22(3):270-274.

3. Askar H, Brouwer F, Lehmensiek M, Paris S, Schwendicke F. The association between loading of restorations and secondary caries lesions is moderated by the restoration material elasticity. J Dent. 2017;58:74-79.

4. Spencer $P, Y e Q$, Park J, et al. Adhesive/dentin interface: The weak link in the composite restoration. Ann Biomed Eng. 2010;38(6):1989-2003.

5. Cadenaro M, Pashley DH, Marchesi G, et al. Influence of chlorhexidine on the degree of conversion and $\mathrm{E}$-modulus of experimental adhesive blends. Dent Mater. 2009;25(10):1269-1274.

6. Campos KdPL, Viana GM, Cabral LM, et al. Self-cured resin modified by quaternary ammonium methacrylates and chlorhexidine: Cytotoxicity, antimicrobial, physical, and mechanical properties. Dent Mater. 2020;36(1):68-75.

7. Jedrychowski JR, Caputo AA, Kerper S. Antibacterial and mechanical properties of restorative materials combined with chlorhexidines. J Oral Rehabil. 1983;10(5):373-381.

8. Slavin YN, Asnis J, Häfeli UO, Bach H. Metal nanoparticles: Understanding the mechanisms behind antibacterial activity. J Nanobiotechnology. 2017;15(1):65.

9. Komabayashi T, Spångberg LSW. Comparative analysis of the particle size and shape of commercially available mineral trioxide aggregates and Portland cement: A study with a flow particle image analyzer. J Endod. 2008;34(1):94-98.

10. Li X, Robinson SM, Gupta A, et al. Functional gold nanoparticles as potent antimicrobial agents against multi-drug-resistant bacteria. ACS Nano. 2014;8(10):10682-10686.

11. García-Contreras R, Argueta-Figueroa L, Mejía-Rubalcava C, et al. Perspectives for the use of silver nanoparticles in dental practice. Int Dent J. 2011;61(6):297-301.

12. Sirelkhatim A, Mahmud S, Seeni A, et al. Review on zinc oxide nanoparticles: Antibacterial activity and toxicity mechanism. Nanomicro Lett. 2015;7(3):219-242.

13. Jeyaraman R, Jeyasubramanian K, Marikani A, Rajakumar G, Rahuman A. Synthesis and antimicrobial activity of copper nanoparticles. Mater Lett. 2012;71:114-116. 
14. Camacho-Flores BA, Martínez-Álvarez O, Arenas-Arrocena MC, et al. Copper: Synthesis techniques in nanoscale and powerful application as an antimicrobial agent. J Nanomater. 2015;2015:ID 415238

15. Meghana S, Kabra P, Chakraborty S, Padmavathy N. Understanding the pathway of antibacterial activity of copper oxide nanoparticles. RSC Adv. 2015;5(16):12293-12299.

16. Argueta-Figueroa L, Morales-Luckie RA, Scougall-Vilchis RJ, OleaMejía OF. Synthesis, characterization and antibacterial activity of copper, nickel and bimetallic $\mathrm{Cu}-\mathrm{Ni}$ nanoparticles for potential use in dental materials. Prog Nat Sci. 2014;24(4):321-328.

17. Fallahzadeh F, Safarzadeh-Khosroshahi S, Atai M. Dentin bonding agent with improved bond strength to dentin through incorporation of sepiolite nanoparticles. J Clin Exp Dent. 2017;9(6):e738-e742.

18. Patel JB, Cockerill FR III, Bradford PA, et al. CLSI document M02-A12. In: Clinical and Laboratory Standards Institute, ed. Performance Standards for Antimicrobial Disk Susceptibility Tests; Approved Standard - Twelfth Edition. Wayne, PA: Clinical and Laboratory Standards Institute; 2015;35(1):72.

19. Argueta-Figueroa L, Torres-Gómez N, García-Contreras R, et al. Hydrothermal synthesis of pyrrhotite $\left(\mathrm{Fe}_{\mathrm{x}-1} \mathrm{~S}\right)$ nanoplates and their antibacterial, cytotoxic activity study. Prog Nat Sci. 2018;28(4):447-455.

20. Hibino $Y$, Kuramochi K, Harashima A, et al. Correlation between the strength of glass ionomer cements and their bond strength to bovine teeth. Dent Mater J. 2004;23(4):656-660.

21. Stanković A, Dimitrijević S, Uskoković D. Influence of size scale and morphology on antibacterial properties of $\mathrm{ZnO}$ powders hydrothermally synthesized using different surface stabilizing agents. Colloids Surf B Biointerfaces. 2013;102:21-28.

22. Khodashenas $B$. The influential factors on antibacterial behaviour of copper and silver nanoparticles. Indian Chem Eng. 2016;58(3):224-239.

23. Breschi L, Maravic T, Cunha SR, et al. Dentin bonding systems: From dentin collagen structure to bond preservation and clinical applications. Dent Mater. 2018;34(1):78-96.

24. Gerth HUV, Dammaschke T, Züchner H, Schäfer E. Chemical analysis and bonding reaction of RelyX Unicem and Bifix composites - a comparative study. Dent Mater. 2006;22(10):934-941.

25. Pal S, Tak YK, Song JM. Does the antibacterial activity of silver nanoparticles depend on the shape of the nanoparticle? A study of the Gram-negative bacterium Escherichia coli. Appl Environ Microbiol. 2007;73(6):1712-1720.

26. Tyas MJ, Burrow MF. Adhesive restorative materials: A review. Aust Dent J. 2004;49(3):112-121; quiz 154.

27. Silva e Souza MH Jr., Carneiro KGK, Lobato MF, de Souza S, Silva e Souza PdAR, de Góes MF. Adhesive systems: Important aspects related to their composition and clinical use. J Appl Oral Sci. 2010;18(3):207-214.

28. Vaidyanathan J, Vaidyanathan TK, Yadav P, Linaras CE. Collagen -ligand interaction in dentinal adhesion: Computer visualization and analysis. Biomaterials. 2001;22(21):2911-2920.

29. Cadenaro M, Maravic T, Comba A, et al. The role of polymerization in adhesive dentistry. Dent Mater. 2019;35(1):e1-e22.

30. Argueta-Figueroa L, Scougall-Vilchis RJ, Morales-Luckie RA, OleaMejia OF. An evaluation of the antibacterial properties and shear bond strength of copper nanoparticles as a nanofiller in orthodontic adhesive. Aust Orthod J. 2015;31(1):42-48.

31. Prakash J, Pivin JC, Swart HC. Noble metal nanoparticles embedding into polymeric materials: From fundamentals to applications. Adv Colloid Interface Sci. 2015;226(Pt B):187-202.

32. Vaidyanathan TK, Vaidyanathan J. Recent advances in the theory and mechanism of adhesive resin bonding to dentin: $A$ critical review. J Biomed Mater Res B Appl Biomater. 2009;88(2):558-578.

33. Armstrong S, Breschi L, Özcan M, Pfefferkorn F, Ferrari M, Van Meerbeek B. Academy of Dental Materials guidance on in vitro testing of dental composite bonding effectiveness to dentin/enamel using micro-tensile bond strength ( $\mu \mathrm{TBS}$ ) approach. Dent Mater. 2017;33(2):133-143.

34. Van Meerbeek B, Peumans M, Poitevin A, et al. Relationship between bond-strength tests and clinical outcomes. Dent Mater. 2010;26(2):e100-e121. 